Turk Med Stud J 2022;9(1):33-5

CASE REPORT

DOI: 10.4274/tmsj.galenos.2021.09.01.07

\title{
CORNEAL ENDOTHELIAL CELL ANALYSIS IN TWO PATIENTS WITH WILSON'S DISEASE AND KAYSER-FLEISCHER RINGS
}

\author{
Ege Gürlü ${ }^{\mathbb{D}}$, Vuslat Gürlü² (D) \\ ${ }^{1}$ Yeditepe University School of Medicine, İstanbul, TURKEY \\ ${ }^{2}$ Trakya University School of Medicine, Department of Ophthalmology, Edirne, TURKEY
}

\section{ABSTRACT}

We aimed to present two patients who were suffering from Wilson's disease along with the Kayser-Fleischer rings. Patient 1: A 15-year-old female patient was admitted to Trakya University School of Medicine Hospital with worsening consciousness, slurred speech, and cognitive impairment. The neurological examination was consistent with Wilson's disease. In the ophthalmologic examination, Kayser-Fleischer rings were revealed. Right corneal cell density was found to be 3270 cell $/ \mathrm{mm}^{2}$ and the left corneal endothelial cell density was found to be $3177 \mathrm{cell} / \mathrm{mm}^{2}$. Patient 2: A 12 -year-old female patient was admitted to the Trakya University School of Medicine Hospital with complaints of difficulty in speaking, involuntary movements of her limbs, and inability to stand or sit. Additional symptoms were microphonia, episodic abnormal posture, and rigidity of the limbs. Corneal endothelial cell density was found to be 3287 cell/ $\mathrm{mm}^{2}$ in the right eye and $3720 \mathrm{cell} / \mathrm{mm}^{2}$ in the left eye. The corneal copper deposition forming a Kayser-Fleischer ring caused no changes in endothelial cell morphology.

Keywords: Corneal endothelium, Kayser-Fleischer ring, microscopy, Wilson's disease

\section{INTRODUCTION}

Wilson's disease is an autosomal recessive disorder of copper metabolism that results in the pathological accumulation of copper in many tissues, primarily the liver, brain, and cornea (1-3). This accumulation results in liver disease such as genetic hemochromatosis and iron overload disorders, and a-1 antitrypsin deficiency, as well as neurological symptoms, and Kayser-Fleischer (KF) rings (1). Although a KF ring is considered the pathognomonic sign of Wilson's disease, it is not confined to this disease. A KF ring can also rarely be found in the presence of chronic cholestatic disorders, such as primary biliary cholangitis and neonatal cholestasis $(2,3)$. A KF ring appears as golden-brown pigment deposits at the level of the Descemet's membrane of the corneal periphery $(2,3)$. It has been reported that KF rings may exist in the asymptomatic phase of the disease, furthermore, they may be a sign of disease severity, and their regression is possible with treatment (2-4). However, the effects of this copper accumulation on the morphology of the endothelial cells are not known.

In this study, a noncontact specular microscope Topcon SP3000P by Topcon Cooperation in Tokyo, Japan was used for endothelial cell analysis. With this method, images of the corneal endothelial cells are taken by a photomicroscope and sent to a computer, which is used with a specular microscope, in order to perform image analysis by software.

The following parameters can be calculated with a specular image, using the instruments' built-in software: endothelial cell density, hexagonality, and coefficient of variances of the endothelial cell layer.

Endothelial cell density is the number of cells in the corneal endothelium per $\mathrm{mm}^{2}$. The mean value for adults is 2400 cells $/ \mathrm{mm}^{2}$ (1500-3500 cells $\left./ \mathrm{mm}^{2}\right)$. Endothelial cell density may decrease with age, in the presence of corneal diseases, after surgical procedures or trauma.

Address for Correspondence: Ege Gürlü, Yeditepe University School of Medicine, İstanbul, TURKEY

e-mail: egegurlu@gmail.com

ORCID iDs of the authors: EG: 0000-0003-4569-9082; VG: 0000-0001-5650-2075.

Received: 12.12.2021 Accepted: 26.12.2021

Cite this article as: Gürlü E, Gürlü V. Corneal endothelial cell analysis in two patients with wilson's disease and kayser-fleischer rings. Turk Med Stud J 2022;9(1):33-5.

Copyright@Author(s) - Available online at https://www.turkmedstudj.com/ 
The standard deviation of the mean cell area divided by the mean cell area gives the coefficient of variation, which is a unitless number normally less than 0.30 .

The percentage of hexagonal cells with 6 apices should ideally approach $100 \%$. Lower percentages indicate a diminishing state of health of the endothelium.

In this case report, we aim to present the corneal endothelial cell analyses of two Wilson's disease patients with KF rings.

\section{CASE REPORTS}

Patient 1: A 15-year-old female patient who exhibited increasingly worsening unconsciousness with slurred speech and cognitive impairment over the previous two weeks was admitted to Trakya University School of Medicine Hospital. Neurological examination showed emotional lability, motor impersistence, hypokinetic dysarthria, postural and intentional tremor affecting the upper extremities, and overall rigidity. Magnetic resonance imaging showed a symmetrical high signal intensity in the putamen, caudate nucleus, the posterior limb of the internal capsule, and parietal white matter on T2 weighted images, with no atrophic changes. Ophthalmic examination found the visual acuity to be $10 / 10$ in both eyes. KF rings were observed in the stroma of both corneal peripheries with biomicroscope (Figure 1). Corneal endothelial cell analysis was performed with a noncontact specular microscope (Figure 2). The right corneal endothelial cell density was found to be $3270 \mathrm{cell} / \mathrm{mm}^{2}$ and the left corneal endothelial cell density was 3177 cell $/ \mathrm{mm}^{2}$ (Table 1). The ophthalmoscopic examination was normal.

Patient 2: A 12-year-old female patient born to nonconsanguineous parents presented with a five-year history of dysarthria, a four-year history of involuntary movements of limbs, and a one-year history of an inability to stand or sit. The microphonia, which was initially present, progressed to aphonia afterwards. The patient also had a history of episodic

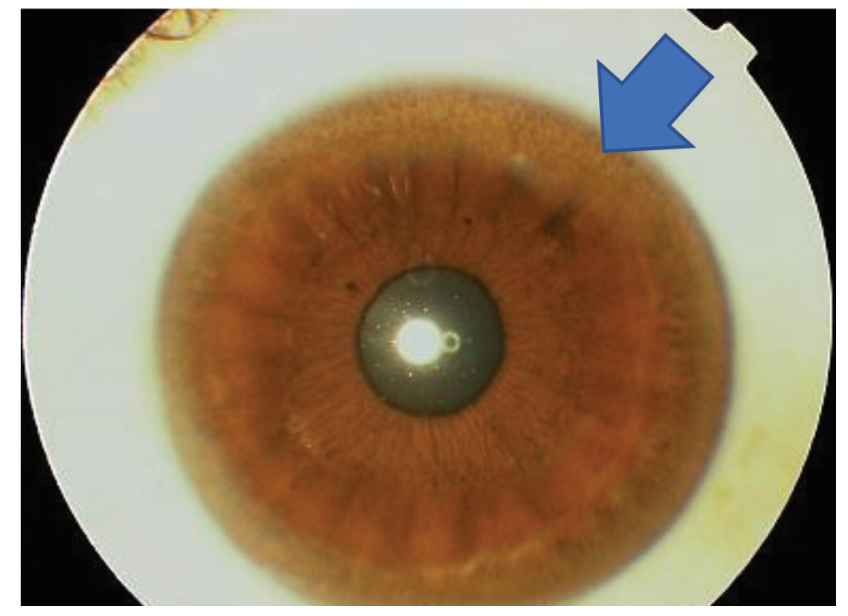

Figure 1: Slit-lamp image of the right eye of patient 1. Kayser-Fleischer ring is observed (shown with the arrow). abnormal posturing and rigidity of limbs. There was no history of jaundice, convulsion, or autonomic disturbances. The ophthalmic evaluation revealed visual acuity to be $10 / 10$ in both eyes. KF rings were observed in both corneas (Figure 3). Corneal endothelial analysis was performed with a noncontact specular microscope (Figure 4), and corneal endothelial cell density was found to be $3287 \mathrm{cell} / \mathrm{mm}^{2}$ in the right eye and $3720 \mathrm{cell} / \mathrm{mm}^{2}$ in the left eye (Table 1). No pathology was detected in the ophthalmoscopy.

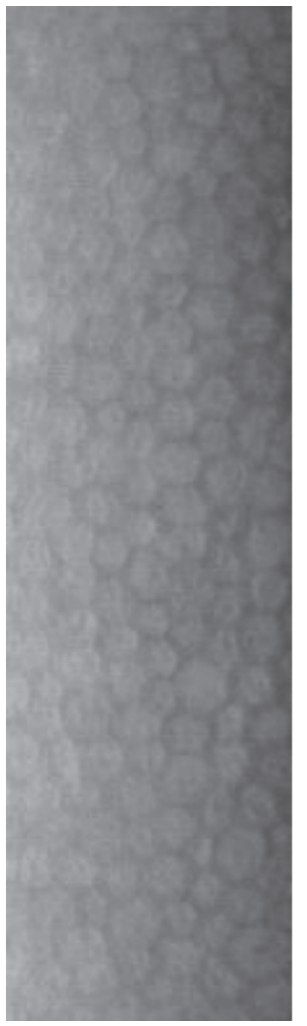

Figure 2: Corneal endothelial cells of the right eye of patient 1 were imaged.

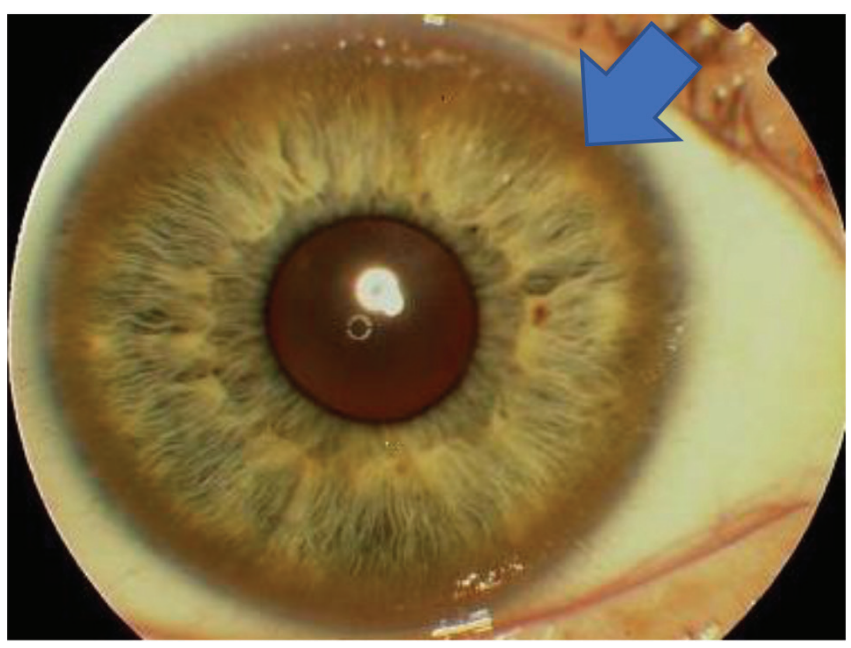

Figure 3: Slit-lamp image of the right eye of patient 2. Kayser-Fleischer ring is observed (shown with the arrow). 
Table 1: Results of the corneal endothelial cell analysis of the patients.

\begin{tabular}{|c|c|c|c|c|}
\hline Cases & Eye & Cell density (cell/mm²) & Coefficient of variances (n) & Hexagonality (\%) \\
\hline \multirow{2}{*}{ Case 1} & Right & 3270 & 25.6 & 77 \\
\hline & Left & 3177 & 29.8 & 68 \\
\hline \multirow{2}{*}{ Case 2} & Right & 3287 & 27.5 & 79 \\
\hline & Left & 3720 & 28.9 & 62 \\
\hline
\end{tabular}

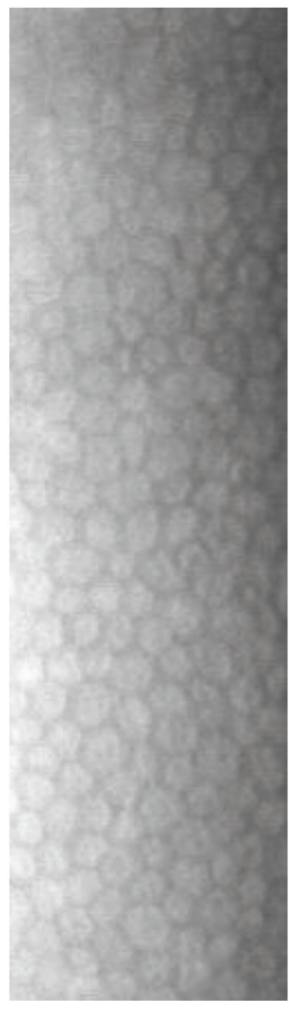

Figure 4: Corneal endothelial cells of the right eye of patient 2 were imaged.

\section{DISCUSSION}

In this case report, corneal endothelial cell analysis results of two Wilson's disease patients with KF rings were found to be normal.

Although there is still much to discover about the pathogenesis of Wilson's disease, it is thoguht to either stem from a lack of serum ceruloplasmin synthesis or from an abnormal protein with a high affinity for copper that binds copper in the tissues (5). Copper deposits were found in the corneal stroma and on the anterior capsule of the lens. Clinically, deposition in the cornea results in a KF ring, while deposition in the anterior capsular lens results in a sunflower cataract. There are studies reporting a remission of both $\mathrm{KF}$ ring and sunflower cataract upon treatment of the disease (3). However, the clinical manifestations of corneal endothelium deficiency have not been reported in patients with a KF ring, and the endothelial morphology of these patients has not yet been studied.

Reactions caused by copper-containing intraocular foreign bodies are known as "ocular chalcosis". Since the intraocular foreign body is usually intravitreal in these patients, toxic effects caused by copper were observed in the vitreous, retina, and lens, while no changes were observed in the cornea (5).

Findings from these patients show that eyes with $\mathrm{KF}$ rings have normal corneal endothelial cell morphology. This observation also leads to the conclusion that the accumulated copper does not cause a toxic or inflammatory effect. The fact that copper, which is known to have toxic effects, did not cause changes in corneas with KF rings can be explained by the fact that copper is protein-bound, and not free. Another possibility is that the abnormal protein, which is assumed to be present in Wilson's disease, may reduce the toxic effects of copper.

In conclusion, it was determined that the KF ring, which is the pathognomonic finding of Wilson's disease, did not cause a morphological change in the corneal endothelium. Longitudinal studies evaluating larger numbers of subjects are still needed to confirm these data.

Ethics Committee Approval: N/A

Informed Consent: Informed verbal consent was obtained from both patients.

Conflict of Interest: The authors declared no conflict of interest.

Author Contributions: Concept: E.G., Design: V.G., Supervision: V.G., Resources: E.G., V.G., Materials: E.G., V.G., Data Collection and/or Processing: E.G., Analysis and/or Interpretation: E.G., Literature search: E.G., Writing Manuscript: E.G., Critical Review: E.G., V.G.

Financial Disclosure: The authors declared that this study received no financial support.

\section{REFERENCES}

1. Schilsky ML, Fink S. Inherited metabolic liver disease. Curr Opin Gastroenterol 2006;22:215-22. [Crossref]

2. Liu M, Cohen EJ, Brewer GJ et al. Kayser-Fleischer ring as the presenting sign of Wilson disease. Am J Ophthalmol 2002;133:832-4. [Crossref]

3. Rodman R, Burnstine M, Esmaeli B et al. Wilson's disease: presymptomatic patients and Kayser-Fleischer rings. Ophthalmic Genet 1997;18:7985. [Crossref]

4. Esmaeli B, Burnstine MA, Martonyi CL et al. Regression of KayserFleischer rings during oral zinc therapy: correlation with systemic manifestations of Wilson's disease. Cornea 1996;15:582-8. [Crossref]

5. Rosenthal AR, Appleton B. Histochemical localization of intraocular copper foreign bodies. Am J Ophthalmol 1975;79:613-25. [Crossref] 